\title{
EDUCACION PARA EL EMPODERAMIENTO: EXPERIENCIAS CON MUJERES RURALES COSTARRICENSES
}

\author{
Lic. Lili Quesada Saravia*
}

Debido a la exclusión social que se vive de manera diferenciada en el interior de la población femenina de las zonas rurales, el Programa Género y Democracia del CEP - ALFORJA trabaja con mujeres de la zona Norte del país con el propósito de poner en práctica la estrategia del empoderamiento con el fin de lograr poder en la toma de decisiones, conocimiento de uno mismo, sentido de seguridad y visión futura y autonomía para resolver necesidades y actuar en la esfera pública.
Due to the social exclusion that is experienced differently by the female population in rural areas, the CEP-ALFORJA program Gender and Democracy - is working with women in the northern part of CostaRica. The program aims to apply empowerment strategies in order to foster decision-making capacity, the knowledge of oneself, a sense of security as well as future vision and autonomy to satisfy needs and act in the public sphere.

* Es licenciada en Sociología y miembro del Programa Género y Democracia del CEP, ALFORJA. 
La siguiente ponencia recoge ideas de diversas elaboraciones propias y del equipo del Programa Género y Democracia del CEP-Alforja, construidas al calor del acompañamiento de experiencias organizativas de grupos de mujeres en la zona norte del país, concretamente en los cantones de Upala, Guatuso y Los Chiles.

Compartiremos primero algunas tesis que consideramos importantes de tomar en cuenta a la hora de abordar la relación entre educación rural y género:

1. Los procesos educativos realmente transformadores son aquellos que se alimentan de propuestas, estilos, metodologias y estrategias tendientes a profundizar apertura de conciencia en las colectividades, de manera que se fortalezcan la visión de poder-alternativo al modelo autoritario y patriarcal-, el análisis crítico, la solidaridad social y la confianza en las propias fuerzas.

2. La construcción de sujeto es un objetivo central de la educación para la transformación. Las nuevas estrategias educativas requieren explorar la comunicación, el diálogo, la integración de la diversidad cultural, la comprensión de los distintos contextos, de los distintos niveles de la construcción de las identidades, el espíritu crítico

3. La capacidad creativa y de invención son parte constitutiva de la propuesta de educación para la transformación. Invención y creatividad que nos lleva a vencer "la impotencia aprendida" para entender nuestra realidad. a identificar los poderes depredadores y autoritarios, a "pasar del malestar a identificar de qué se trata" (Lagarde).

Estamos hablando entonces de potenciar la Autonomia Creativa en cada acto que nos lleve a descodificar y problematizar la realidad.

4. En este marco concepcional podemos entonces ubicar las posibilidades que nos ofrece el enfoque de género. Precisemos primero que el enfoque o perspectiva de género, en términos generales, no es otra cosa que la consideración de las necesidades y visiones diferenciadas entre hombres y mujeres respecto a su ubicación en el mundo y de sus distintas percepciones de vida, todo ello en el contexto de relaciones desiguales de poder entre los géneros. El enfoque de género nos permite entonces abordar la temática del ejercicio de derechos - en este caso del derecho a la educación- desde la vivencia de hombres y mujeres de una posesión diferenciada de recursos en lo económico y lo social, lo cultural y lo simbólico

5. La relación entre los procesos educativos y el género supone tomar en cuenta al menos dos situaciones fundamentales: a. que hombres y mujeres accesan a los recursos y espacios educativos desde socializaciones distintas y que, por lo tanto, ello exige precisar la particular vinculación de las mujeres con lo educativo $y, b$. que en el aspecto social tanto hombres como mujeres 
vivimos sujetos a fenómenos de discriminación y empobrecimiento, impactándose con ello las posibilidades de acceso y calidad educativa: las mujeres en condiciones de pobreza son las que usualmente tienen que bregar con las mayores cargas y limitaciones para superar sus niveles educativos y de capacitación.

\section{La pobreza de las mujeres...}

Esta última tesis nos coloca de manera directa en la temática de la pobreza de las mujeres rurales. Como bien han apuntado diversos autores, más que hablar de pobreza se debería hablar de exclusión social, esta incluye vivencias de marginación, estigmatización y discriminación.

Esa exclusión social se vive de manera diferenciada en el interior de la población femenina (mujeres urbanas, mujeres rurales, mujeres diversas en edad, mujeres responsables de familia, mujeres migrantes, etc.).

¿Qué es ser una mujer rural pobre? Es ante todo no tener acceso a los recursos ni tener medios para generar ingresos (además de la vivencia de otras muchas necesidades).

La pobreza tiene una dimensión subjetiva personal que hace que en un mismo grupo de pobladoras rurales esta se viva con distintos grados de empoderamiento-desempoderamiento. Con distintas "voces".

"La falta de voz" tiene un peso muy importante en la vivencia de la pobreza. Esto en el sentido de que para enfrentarla, el recurso del empoderamiento para verbalizar y negociar la demanda es fundamental.

Cuando decimos verbalizar y negociar de lo que estamos hablando, en primer lugar, es de que se asuma como un derecho de ciudadania el acceso a los recursos públicos. Ya no se trata de la mujer rural haciendo fila en el IMAS para "pedir una ayuda". Se trata de mujeres rurales que enfrentan la pobreza desde la conciencia de sus derechos.

El otro aspecto, relacionado con el anterior, es la elección de la colectividad como soporte para encauzar la búsqueda de soluciones a la pobreza. En efecto, la experiencia demuestra que el hecho de organizarse ya de por sí representa un paso importante para las mujeres, que impulsa acciones cada vez de mayor envergadura en la relación con las instituciones.

Otra situación compleja tiene que ver con cómo orientar los procesos de las mujeres rurales en acceso a recursos y empleo de manera que éstas vayan resolviendo "en lo concreto" el mejoramiento de la calidad de vida material. Las mujeres exigen manejo de dinero propio, proyectns productivos que generen ganancia, opciones efectivas de capacitación laboral, etc. 
¿Qué es ser una mujer rural pobre? Es ante todo no tener acceso a los recursos ni tener medios para generar ingresos (además de la vivencia de otras muchas necesidades).
Para lograr soluciones, las mujeres líderes rurales han venido aprendiendo a relacionarse con los políticos de maneras cada vez más pragmáticas. La cultura política en cste país sigue el patrón clientelista que utiliza a su favor las necesidades de las mu-

jeres. En este marco se plantean ofrecimientos. Las mujeres organizadas juegan con distintas opciones. Lo que parece ser claro es que la confianza en las propias fuerzas es la que representa la clave más importante. Confianza en las propias fuerzas que se traduce en movilización, presión social, elaboración de demanda, procesos de negociación, seguimiento de políticas...

Los gobiemos de turno poco han resuelto para el mejoramiento sustantivo de la pobreza de las mujeres rurales, a juzgar por el propio testimonio de las pobladoras rurales y la situación de determinados indicadores de calidad de vida.

\section{El empoderamiento...}

El otro punto al que me quiero referir en esta introducción es al empoderamiento. Éste puede verse más bien como una estrategia, es decir, un conjunto de acciones y procesos orientados básicamente al logro de:

- mayor poder de tomar decisiones,

- conocimiento de una misma (en los aspectos individual y colectivo),

- sentido de seguridad y visión de futuro,

- capacidad de resolver con autonomía las necesidades de sobrevivencia economica,

- capacidad de actuar eficazmente en la esfera pública.

El empoderamiento tiene relación con procesos que vayan dotando de recursos -materiales y simb6licos-y alimentando las fuentes intemas de poder a varios niveles. Tiene que ver con una capacidad, una facultad para hacer y transformar.

Para empoderarse tenemos que deconstnuir las subordinaciones interiorizadas. Es desarrollar la capacidad crítica, de cuestionamiento, de autorreconocimiento y reconocimiento en los(as) otros(as) de los condicionamientos para cumplir con los mandatos. Mandatos de una sociedad patriarcal que acogemos desde nuestra primera socialización infantil y que con los años se van refinando e interiorizando como parte "natural" de nuestra personalidad. 
El empoderamiento nos lleva al protagonismo que puede trastocar el escenario público. "El proceso de desafío de las relaciones de poder existentes, así como el de obtención de un mayor control sobre las fuentes de poder, pueden ser llamados empoderamiento" (Srilatha Batliwala 1997).

Esta estrategia de empoderamiento nos coloca frente al lema: "Derecho a tener derechos" (frase de Elizabeth Jelin). Es decir, no se trata solamente de que nos concedan un derecho, sino de poder ejercerlo de manera activa, y sobre, todo incidir en las decisiones que afectan ese derecho.

Nos gusta la definición de Sharma (citada por Srilatha Bathwala, 1997).

"El término empoderamiento se refiere a una gama de actividades que van desde la autoafirmación individual hasta la resistencia colectiva, la protesta y la movilización para desafiar las relaciones de poder. ...El empoderamiento comienza cuando pueden reconocerse las fuerzas sistémicas que oprimen, así como cuando actúan para cambiar las relaciones de poder existentes. El empoderamiento, por tanto, es un proceso orientado a cambiar la naturaleza y la dirección de las fuerzas sistémicas, que marginan a la mujer y a otros sectores en desventajas en un contexto dado".

\section{Entrando en materia... ubicando el contexto}

A partir de estas reflexiones previas, podemos ahora situarnos en el contexto que recrea las estrategias impulsadas por el Cep Alforja en el acompañamiento de procesos organizativos y de capacitación con mujeres líderes de la zona norte del país.

La región Huetar Norte tiene poco menos de 100,000 mujeres pobladoras. En el año 2000, se registró una población de hogares pobres en la región del $30 \%$. Un dato que evidencia el deterioro de calidad de vida es que Los Chiles. Guatuso y Upala están entre los 10 cantones con mayor analfabetismo del país.

Veamos la situación cotidiana de las pobladoras de esta región, desde las palabras de miembras de la Asociación de Mujeres de El Coroso, en Los Chiles:

"Las mujeres aquí en la zona Norte vivimos en pobreza, faltan fuentes de trabajo y trabajamos en lo que aparezca: cortando naranjas, arrancando frijoles, recogiendo maíz, trabajando en las empacadoras de tubérculos. También vivimos llenándonos de chiquillos, muy marginadas, aguantando agresiones. Las jóvenes se embarazan y muy jóvenes se van de la casa. No hay educación ni formación, la mayor parte 
no saben leer ni escribir. La salud es muy mala y no tenemos diversión de ninguna especie.

Las necesidades que tenemos como mujeres son de tener trabajo, ingresos, poder disponer de dinero. Que nos miren bien. No ser maltratadas. Ser tomadas en cuenta. Ser valoradas, poder divertirse. No ser agredidas, tener oportunidades de educación, ser mejor atendidas en salud, educarnos para tener menos embarazos...» (Taller, agosto 2000).

Estamos hablando de poblaciones femeninas rurales donde el derecho de expresión y de tomar decisiones está fragmentado o simplemente negado: donde se trabaja sin obtener reconocimiento; donde se autorreprime y se limita el derecho al placer y la recreación: donde muchas se perciben y son percibidas como incapaces de sobrevivir por sí mismas en este mundo: donde el analfabetismo por desuso refucrza de manera profunda las pocas oportunidades de superación; donde la falta de acceso a recursos económicos y productivos es la principal problemática sentida.

Los grupos de mujeres rurales en esta zona (similar al resto del país) se caracterizan por ser pequeños en membresía, con serias limitaciones internas (en organización, planificación, financiamiento, proyección, etc.) y una clara demanda priorizada en términos de acceso a recursos de diversa índole (tierra. crédito, asistencia técnica). Estos pequeños grupos de mujeres rurales presentan un desafío fundamental: cómo encauzar la necesidad y la demanda sentidas de acceso a recursos hacia la acción eficaz que formula propuestas, negocia y gana derechos. En ausencia de estrategias articuladas en lo económico y lo socioorganizativo, que pongan en contacto las experiencias de estos grupos, consideramos poco efectivos y muy lentos los resultados y los impactos.

Las demandas principales que han venido identificando las líderes de la zona están asociadas a:

- Salario digno y estable

- Vivienda digna.

- Participación en la toma de decisiones.

- Capacitación.

- Fuentes de trabajo.

- Crédito a bajos intereses.

- Mejorar calidad de los servicios de salud.

- Atención a mujeres agredidas.

- Apoyo a las jóvenes.

- Mejorar el nivel educativo.

$\checkmark \quad$ Libertad de expresión. 


\section{La estrategia...}

La estrategia que hemos seguido se caracteriza por:

1. La apuesta a la autoafirmación de las mujeres. Es asi porque partimos del hecho de que para ejercer poder, como personas y ciudadanas, lo primero que tenemos que trabajar es la pregunta quién soy y qué quiero y necesito.

2. El fortalecimiento del sujeto colectivo, en este caso, del movimiento social de mujeres rurales. La democracia tiene que resignificarse: en tanto las mujeres participen demandando, proponiendo, vigilando... se constituyen como actoras en el ejercicio de la democracia.

3. La búsqueda de procesos de incidencia. Esto nos lleva al tema del diseño y negociación de Agendas Locales o Regionales de las mujeres.

4. Pone el acento en la construcción de poder ciudadano local desde las mujeres. Entendemos por acción ciudadana local desde las mujeres:

- gestiones para accesar a recursos diversos a nivel local,

- ejercicio del derecho a estar informadas en la zona,

- formación para la acción social y la acción política local,

- acciones de vigilancia social hacia el gobierno local y las instituciones que actúan en la zona,

- acciones para defender la autonomía grupal,

- gestiones para colocar las necesidades de las mujeres en la agenda local, - promoción de la participación política de las mujeres en la localidad.

Resumiríamos las acciones estratégicas del CEP Alforja hacia las mujeres rurales de la zona norte del país (vigente para el período 2000-2002), en las siguientes:

- Reforzar la construcción de «ciudadana nural sujeta de derechos» (ya no es más la "campesina que va a pedir una ayuda" en la relación con las instituciones).

- Consolidar los espacios cantonales de coordinación de los grupos de mujeres, con el fin de fortalecer el movimiento y posibilitar mejores condiciones organizativas para el impulso de las acciones de incidencia.

- A vanzar en la construcción de pactos entre las mujeres (lideres de grupos y municipalistas).

- Capacitar a las líderes de la zona para el diseño y negociación de una Agenda Regional. 
- Encauzar el proceso negociativo de la Agenda Regional por parte de una Comisión Intercantonal de Líderes de cara a la toma de compromisos de la nueva administración gubernamental e institucional (2002-2006).

Concluimos que este compartir metodológico y estratégico de la experiencia con el señalamiento de los logros alcanzados hasta el momento son:

- Cuarenta mujeres líderes de tres cantones de la zona han ampliado su información sobre los programas que realizan las instituciones en la zona, sobre la noción de ciudadanía y el ejercicio de derechos, además de ver refortados sus procesos de empoderamiento personal.

- Se ha propiciado el acercamiento entre líderes de los grupos y mujeres municipalistas, facilitándose así las condiciones para un futuro pacto de trabajo que incida en los gobiernos municipales.

- Creación de Redes cantonales de Grupos de mujeres en Upala, Guatuso y Los Chiles

- Inicio del proceso de elaboración de la Agenda Regional de Mujeres de la Zona Norte.

- En marzo del 2002 esperamos que las líderes de la zona estén en condiciones de presentar públicamente a los nuevos poderes oficiales, tanto del gobierno central como local, el documento de Agenda Regional, para dar paso al proceso negociativo.

Los desafíos siguen relacionándose con el potenciamiento de la capacidad movilizadora y de negociación de las líderes. También con los niveles de apertura y sensibilidad que puedan mostrar las nuevas autoridades institucionales para dar respuesta efectiva a las demandas planteadas por las mujeres... 